\title{
Multi Attribute Decision Making Approach to Optimize the Product Mix in Assignment Problems using Fuzzy Group Parameters
}

\author{
B. Chellappa \\ Associate Professor, \\ Department of Mathematics \\ Alagappa Govt. Arts College \\ Karaikudi, India
}

\author{
S.V. Manemaran \\ Assistant Professor \\ Department of Mathematics \\ Oxford Engineering College \\ Tiruchirappalli, India
}

\begin{abstract}
Inventory models in which the demand rates on the inventory level are based on the common real life observation that greater product availability tends to stimulate more sales. Theory of constraints (TOC) is a production planning philosophy that tries to improve the throughput of the system management of inventory levels. Due to the existing of inventory levels in a production system the demands of all products can not be fully met. So one of the most important decisions made in production systems is product mix problem. Although many algorithms have been developed in the fields using the concept of theory of constraints. This paper benefits from a variety of advantages. In order to consider the importance of all inventory levels, group decision making approach is applied and the optimal product mix is reached. In the algorithm presented in this paper, each inventory level is considered as a decision maker. The new algorithm benefits from the concept of fuzzy group decision making and optimizes the product mix problem in inventory environment where all parameters are fuzzy values.
\end{abstract}

\section{Keywords}

Fuzzy group decision making, product mix optimization, multiattribute decision making, theory of constraints, inventory level cost, Trapezoidal fuzzy number.

\section{INTRODUCTION}

Theory of constraints (TOC) which has been first introduced in the Goal [4] is a production planning philosophy that aims to improve the system through put by efficient use of inventory levels. In this paper product mix optimization is considered as a decision making problem. Regarding this analogy decision making criteria should be first defined [5]. Two important criteria are throughput and the later delivery cost. Later delivery cost is the most of mission one unit of each product. Assuming each inventory level as a decision maker [6], product mix optimization is a group decision making problem. In all previous researchers all parameters (such as processing time, demand etc) are assumed as crisp values. In this paper, a new algorithm is developed to optimize the product mix problem with all inputs are fuzzy values and Borda methods is used in group decision making process as ordinal techniques are preferred to cardinal ones [9].

\section{ALGORITHMS}

The following notations are used in the new algorithm.

$\mathrm{t}_{\mathrm{ij}}=$ Processing time of product $\mathrm{i}$ on resource $\mathrm{j}$.

$\mathrm{D}_{\mathrm{i}}=$ Demand of product $\mathrm{i}$.

$\mathrm{Sp}_{\mathrm{i}}=$ Selling price of product $\mathrm{i}$.

$\mathrm{Rm}_{\mathrm{i}}=$ Raw material cost of product $\mathrm{i}$.

$\mathrm{Ac}_{\mathrm{j}}=$ Available capacity of resource $\mathrm{j}$.

$R c_{j}=$ Required capacity of resource $j$.

$\mathrm{n}=$ number of products.

$\mathrm{m}=$ number of inventory levels.

In this paper, all parameters are considered Trapezoidal fuzzy numbers and are shown as $(\mathrm{x}, \mathrm{y}, \mathrm{z}, \mathrm{p})$ where $\mathrm{x}<\mathrm{y}<\mathrm{z}<\mathrm{p}, \mu_{\mathrm{y}}=1$ and $\mu_{\mathrm{x}}=\mu_{\mathrm{z}}=0$. So let define $\mathrm{t}_{\mathrm{ij}}, \mathrm{D}_{\mathrm{i}}, \mathrm{Sp}_{\mathrm{i}}, \mathrm{Rm}_{\mathrm{i}}$, and $\mathrm{Ac}_{\mathrm{j}}$ as follows.

$t_{i j}=\left(L_{i j}, M_{i j}, U_{i j}, V_{i j}\right), D_{i}=\left(L_{i}^{\prime}, M_{i}^{\prime}, U_{i}^{\prime}, V_{i j}^{\prime}\right)$

$\mathrm{Sp}_{\mathrm{i}}=\left(\mathrm{A}_{\mathrm{i}}, \mathrm{B}_{\mathrm{i}}, \mathrm{C}_{\mathrm{i}}, \mathrm{D}_{\mathrm{i}}\right), \mathrm{Rm}_{\mathrm{i}}=\left(\mathrm{A}_{\mathrm{i}}{ }^{\prime}, \mathrm{B}_{\mathrm{i}}{ }^{\prime}, \mathrm{C}_{\mathrm{i}}{ }^{\prime}, \mathrm{D}_{\mathrm{j}}{ }^{\prime}\right)$,

$\operatorname{Ac}=\left(\alpha_{\mathrm{i}}, \beta_{\mathrm{i}}, \chi_{\mathrm{i}}, \psi_{\mathrm{i}}\right)$

Step - 1: Identify the system of inventory levels. As $t_{i j}$ and $D_{i}$ are positive fuzzy numbers, the required capacity of resource $j$ is calculated as follows.

$$
\begin{aligned}
R_{C_{j}} & =\sum_{i=1}^{n} t_{i j} D_{i} \\
& =\left(\sum_{i=1}^{n} L_{i j} L_{i}^{\prime}, \sum_{i=1}^{n} M_{i j} M_{i}^{\prime}, \sum_{i=1}^{n} U_{i j} U_{i}^{\prime}\right)
\end{aligned}
$$


For simplicity $R c_{j}$ is shown as $\left(a_{j}, b_{j}, c_{j}, d_{j}\right)$. In order to determine whether ' $\mathrm{j}$ ' is an inventory level. $\mathrm{Rc}_{\mathrm{j}}$ and $A c_{j}$ are compared using fuzzy ranking techniques. Due to the efficiency of ranking of ranking methods based on lest and right scores, the method by Chen is applied (Chen and Hwang 1992). In this method, right and left scores of a fuzzy number refer to its intersection with the fuzzy max and the fuzzy min respectively. The fuzzy max and fuzzy $\min$ are defined as follows,

$$
\begin{gathered}
\mu_{\text {max }}(x)=\frac{x-x \mu_{\text {min }}}{x_{\text {max }}-x_{\text {min }}} \\
\mu_{\text {min }}(x)=\frac{x_{\text {max }}-x}{x_{\text {max }}-x_{\text {min }}}
\end{gathered}
$$

where $\mathrm{x}_{\max }$ is $\max \left(\mathrm{b}_{\mathrm{i}}, \chi_{\mathrm{i}}\right)$ and $\mathrm{x}_{\min }\left(\mathrm{a}_{\mathrm{i}}, \alpha_{\mathrm{i}}\right)$. As $\mathrm{Rc}_{\mathrm{i}}$ and $\mathrm{Ac}_{\mathrm{i}}$ are trapezoidal fuzzy numbers, they are convex, continuous and normal. So their right scores may be determined by taking the intersection of their non-increasing part and $\mu_{\max }(\mathrm{x})$. Similarly, their scores are determined by taking the intersection of their non-decreasing part and $\mu_{\min }(\mathrm{x})$. As higher right score $\mu_{\mathrm{R}}(\mathrm{x})$ and lower left score indicate large fuzzy number, the total score of Rc and Ac are defined as follows.

$\mu_{\text {Total }}\left(R_{C_{j}}\right)=\frac{\mu_{\text {Right }}\left(R_{C_{j}}\right)+1-\mu_{\text {Left }}\left(R_{C_{j}}\right)}{2}$

$\mu_{\text {Total }}\left(A_{C_{j}}\right)=\frac{\mu_{\text {Right }}\left(A_{C_{j}}\right)+1-\mu_{\text {Left }}\left(A_{C_{j}}\right)}{2}$

If $\mu_{\text {Total }}\left(R c_{j}\right)>\mu_{\text {Total }}\left(A c_{j}\right)$, then $\mathrm{j}$ is an inventory level.

Step - 2: Form decision matrices. Throughput $\left(X_{\mathrm{ij}}\right)$ is the first criterion considered in optimizing product mix. It is calculated as $\mathrm{X}_{\mathrm{ik}}=\mathrm{Cm}_{\mathrm{i}} / \mathrm{t}_{\mathrm{ij}} \quad \ldots \ldots \ldots \ldots$ (5) Where $\mathrm{Cm}_{\mathrm{i}}$ is determined by the difference of the selling price and raw material cost of the product $i$.

$\mathrm{Cm}_{\mathrm{i}}=\left(\mathrm{A}_{\mathrm{i}}-\mathrm{C}_{\mathrm{i}}{ }^{\prime}, \mathrm{B}_{\mathrm{i}}-\mathrm{B}_{\mathrm{i}}{ }^{\prime}, \mathrm{C}_{\mathrm{i}}-\mathrm{A}_{\mathrm{i}}{ }^{\prime}\right)$

As $\mathrm{Cm}_{\mathrm{i}}$ and $\mathrm{t}_{\mathrm{ij}}$ are trapezoidal fuzzy numbers, $\mathrm{X}_{\mathrm{ik}}$ is calculated as follows.

$X_{i k}=\left(A_{i} / U_{i j}, B_{i} / M_{i j}, C_{i} / L_{i j},\right)$
The other criteria are late delivery cost (Rashidi Komijan and Sadjadi 2005). Although it is a crisp value in most cases, it is considered as $\operatorname{LDC}_{i}\left(\mathrm{p}_{\mathrm{i}}, \mathrm{q}_{\mathrm{i}}, \mathrm{r}_{\mathrm{i}}\right)$. Decision matrix of decision make $\mathrm{K}$ can be set as follows.

$$
\mathrm{DM}_{\mathrm{k}}=Z_{i}\left(\begin{array}{cc}
X_{1 k} & L D C_{1} \\
\cdot & \cdot \\
X_{i k} & L D C_{i} \\
\cdot & \cdot \\
X_{n k} & L D C_{n}
\end{array}\right)
$$

Where $r_{i j k}$ is the rank of alternative ' $\mathrm{i}$ ' assigned by decision maker ' $k$ ' given the criterion ' $j$ '.

Step - 4: For each criterion, set an agreed matrix that shows the ranks assigned to the alternatives by decision makers.

$$
\begin{aligned}
& 1 . . \quad k \text {. . } m \\
& Z_{1}\left(r_{1 j 1} \cdot \cdot \cdot r_{1 j k} \cdot \cdot \cdot r_{1 j m}\right) \\
& \mathrm{R}_{\mathrm{j}}{ }^{\prime}=Z_{i} r_{i j 1} \cdot \cdot \cdot r_{i j k} \cdot \cdot \cdot r_{i j m} \\
& Z_{n}\left(r_{n j 1} \cdot \cdot \cdot r_{n j k} \cdot \cdots r_{n j m}\right)
\end{aligned}
$$

Step - 5: Form Borda score matrices.

$$
\begin{aligned}
& 1 \text {. . } k \text {. . } m
\end{aligned}
$$

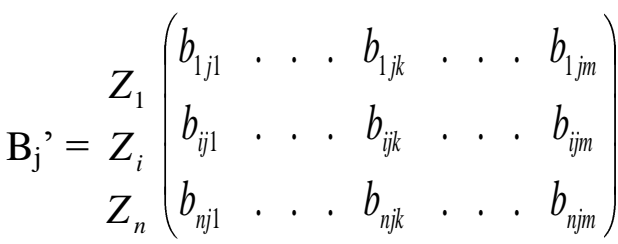

Where $\mathrm{b}_{\mathrm{ijk}}=\mathrm{n}-\mathrm{r}_{\mathrm{ijk}}$

Step - 6: Set score matrices by summing the values of each row.

$$
\left.\mathrm{SM}_{\mathrm{j}}=\begin{array}{c}
Z_{1} \\
Z_{i} \\
\cdot \\
Z_{n} \\
S_{i j} \\
\cdot \\
S_{n j}
\end{array}\right)
$$

Where $S_{i j}=\sum_{k=1}^{n} b_{i j k}$ 
Step - 7: Set the agreement matrix. Firstly, values of the score matrices should be ranked. Then the agreement matrix is set by aggregating these ranks.

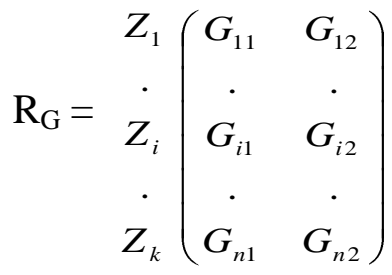

Where $G_{i, 1}$ and $G_{i, 2}$ are the agreement ranks of alternative ' $i$ ' given through put and late delivery cost respectively.

Step - 8: Set the collective weighted agreement matrix. It is an $\mathrm{n} \times \mathrm{n}$ matrix in which rows and columns are alternatives and ranks respectively.

$$
Q=\left[q_{i} \ell=\sum_{j=1}^{2} G_{i}{ }^{\prime} \ell_{j} W_{j}\right]
$$

Where $w_{i}$ is the weight of criteria ' $j$ ' and $G_{i ' \ell j}=1$ if alternative $i$ is assigned rank $\ell$ given criterion $j$, otherwise it is zero.

Step - 9: Formulate a mathematical model. In order to obtain final ranks of alternatives, the classical assignment problem is considered. This is a zero-one model in which decision variable $\left(\mathrm{x}_{\mathrm{i}} \ell\right)$ is one if rank $\ell$ is assigned to alternative $\mathrm{i}$, otherwise it is zero.

$$
\operatorname{Max} \sum_{i=1}^{n} \sum_{\ell=1}^{n} q_{i} \ell x_{i} \ell
$$

Subject to $\sum_{i=1}^{n} x_{i} \ell=1, \ell=1,2,3, \ldots \ldots \ldots . . . n$

$$
\sum_{\ell=1}^{5} x_{i} \ell=1, i=1,2,3, \ldots \ldots \ldots . . . n
$$

$\mathrm{x}_{\mathrm{i}} \ell$ is binary. Solving the above model represents the final ranking of alternatives.

\section{NUMERICAL EXAMPLE}

A company produces five products a, b, c, d, e. Demand, selling price, raw material cost and delivery cost of the products are trapezoidal fuzzy numbers as shown in Table 1. Processing time and available capacity are shown in Table 2.

\begin{tabular}{|c|c|c|c|c|c|}
\hline $\begin{array}{c}\text { Pr } \\
\text { od } \\
\text { uct }\end{array}$ & Demand & $\begin{array}{c}\text { Selling } \\
\text { price } \\
\text { (dollar) }\end{array}$ & $\begin{array}{c}\text { Raw } \\
\text { material } \\
\text { cost } \\
(\text { dollar) }\end{array}$ & $\begin{array}{c}\text { CM } \\
\text { (SP- } \\
\text { RMC) }\end{array}$ & $\begin{array}{c}\text { Late } \\
\text { delivery } \\
\text { cost } \\
\text { (dollar) }\end{array}$ \\
\hline a & $(4,6,7,9)$ & $(\mathbf{3 , 5 , 7 , 1 0 )}$ & $(\mathbf{5 , 7 , 1 0 , 1 2 )}$ & $(\mathbf{3 , 4 , 6 , 9 )}$ & $\mathbf{9}$ \\
\hline b & $(\mathbf{2 , 3 , 5 , 9 )}$ & $(\mathbf{5 , 7 , 9 , 1 3 )}$ & $(\mathbf{4 , 6 , 9 , 1 2 )}$ & $(\mathbf{5 , 6 , 7 , 1 0 )}$ & 4 \\
\hline c & $(\mathbf{7 , 9 , 1 0 , 1 2 )}$ & $(\mathbf{6 , 7 , 9 , 1 0 )}$ & $(\mathbf{7 , 9 , 1 0 , 1 3 )}$ & $(\mathbf{6 , 7 , 1 0 , 1 3 )}$ & $\mathbf{2}$ \\
\hline d & $(\mathbf{4 , 5 , 7 , 9 )}$ & $(\mathbf{5 , 7 , 1 2 , 1 5 )}$ & $\mathbf{( 7 , 9 , 1 3 , 1 5 )}$ & $(\mathbf{2 , 4 , 1 0 , 1 3 )}$ & 1 \\
\hline e & $(\mathbf{5 , 7 , 1 0 , 1 4 )}$ & $(\mathbf{4 , 1 0 , 1 3 , 1 5 )}$ & $(\mathbf{3 , 7 , 9 , 1 3 )}$ & $(\mathbf{2 , 3 , 1 0 , 1 4 )}$ & $\mathbf{8}$ \\
\hline
\end{tabular}

Table - 1 Demand, selling price, Raw material cost of each product and late delivery cost.

\begin{tabular}{|c|c|c|c|c|}
\hline Station - 1 & Station - 2 & Station - 3 & Station - 4 & Station - 5 \\
\hline$(\mathbf{3 , 7 , 1 0 , 1 3 , 1 )}$ & $(4,7,10,14,1)$ & $(5,15,20,30)$ & $(5,10,15,20)$ & $(10,15,20)$ \\
\hline$(10,15,20,30)$ & $(5,15,20,35)$ & $(5,10,15,25)$ & $(10,15,20,30)$ & $(\mathbf{5 , 1 5 , 2 0 , 2 5 )}$ \\
\hline$(5,10,20,40)$ & $(10,15,20,35)$ & $(10,15,25,30)$ & $(5,10,15,25)$ & $(10,15,25,35)$ \\
\hline$(10,15,25,30)$ & $(10,20,30,40)$ & $(5,10,15,25)$ & $(10,15,25,35)$ & $(15,20,25,40)$ \\
\hline$(5,10,15,30)$ & $(0,0,0,0)$ & $(0,0,0,0)$ & $(5,10,15,20)$ & $(0,0,0,0)$ \\
\hline
\end{tabular}

Table - 2 Processing time of each product.

The available capacity is $(300,950,2000,2500)$, $(250,1250,3500,4000), \quad(150,650,1200,1800)$,

$(175,600,1000,1200),(200,350,600,800)$.

Step - 1: The required capacity of each station is calculated as follows.

$$
\begin{aligned}
\mathrm{Rc}_{1} & =\sum_{i=a}^{e} t_{i 1} D_{i}=(275,900,1900,2400) \\
\mathrm{Rc}_{2} & =\sum_{i=a}^{e} t_{i 2} D_{i}=(225,725,1800,2200) \\
\mathrm{Rc}_{3} & =\sum_{i=a}^{e} t_{i 3} D_{i}=(200,750,1325,1365) \\
\mathrm{Rc}_{4} & =\sum_{i=a}^{e} t_{i 4} D_{i}=(275,900,2000,2100)
\end{aligned}
$$


$\mathrm{Rc}_{5}=\sum_{i=a}^{e} t_{i 5} D_{i}=(275,975,1825,2000)$

Since $\mathrm{Rc}_{2}>\mathrm{Ac}_{2}, \mathrm{Rc}_{3}>\mathrm{Ac}_{3}, \mathrm{Rc}_{5}>\mathrm{Ac}_{5}$ so stations 2,3 and 5 are inventory level but station 1 is not. It can be easily concluded whether station 4 is an inventory level. $\quad \mathrm{Ac}_{4}$ and $\mathrm{Rc}_{4}$ are compared using left and right.

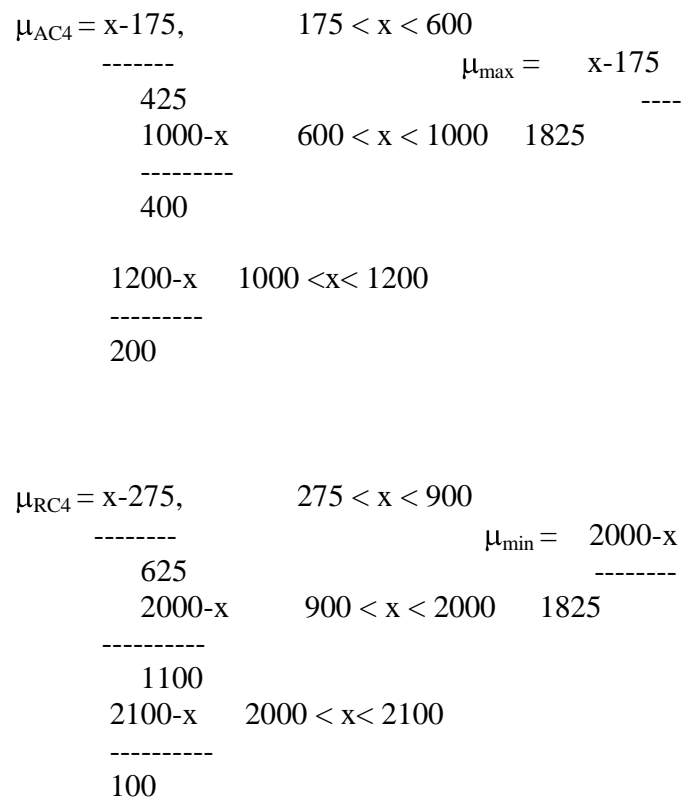

This right score of fuzzy number's are the intersecting of their non-increasing parts and $\mu_{\max }(\mathrm{x})$.

$\mu_{\text {Right }}\left(\mathrm{Ac}_{4}\right)=0.42$ and $\mu_{\text {Right }}\left(\mathrm{Rc}_{4}\right)=0.53$ similarly the left and total scores of $\mathrm{Rc}_{4}$ and $\mathrm{Ac}_{4}$ are calculated as.

$\mu_{\text {Left }}\left(\mathrm{Ac}_{4}\right)=076$ and $\mu_{\text {Left }}\left(\mathrm{Rc}_{1}\right)=0.68, \quad \mu_{\text {Total }}\left(\mathrm{Ac}_{4}\right)=0.32$ and $\mu_{\text {Total }}\left(\mathrm{Rc}_{4}\right)=0.41$. So $\mathrm{Rc}_{4}$ is greater then $\mathrm{Ac}_{4}$ and state 4 is an inventory level.

Step - 2: Late delivery costs are assumed crisp values; however, the algorithm would be efficient, if they were fuzzy. Decision matrices are set as follows. Note that the first column of the following matrices are calculated by dividing $\mathrm{C}_{\mathrm{mi}}$ into $\mathrm{t}_{\mathrm{ij}}$

$$
\mathrm{DM}_{1}=\begin{gathered}
a \\
b \\
c \\
c \\
d \\
e
\end{gathered}\left(\begin{array}{cccc}
0.32 & 2 & 12 & 5 \\
0.36 & 2.13 & 2.7 & 2.5 \\
0.32 & 0 & 5 & 8 \\
0.5 & 2.22 & 8 & 8 \\
0.42 & 2.5 & 7 & 2.4
\end{array}\right)
$$

$\mathrm{DM}_{2}=\begin{gathered}a \\ b \\ c \\ d \\ d\end{gathered}\left(\begin{array}{cccc}0.4 & 6 & 8 & 5 \\ 0.42 & 2.11 & 5 & 4.2 \\ 0.28 & 0.57 & 2 & 5.3 \\ 0.42 & 2 & 9 & 2.8 \\ - & - & - & -\end{array}\right)$

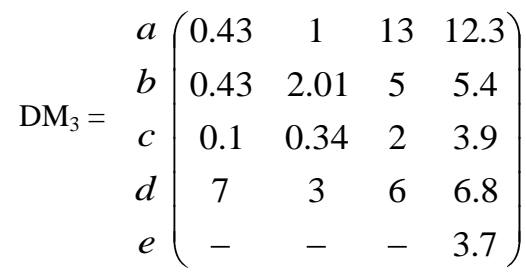

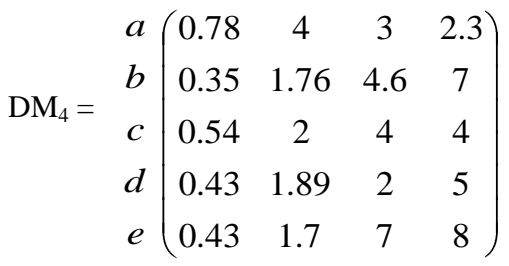

$\mathrm{DM}_{5}=\begin{gathered}a \\ b \\ c\end{gathered}$

Step - 3: Ranking alternatives given the first criterion is done by applying left and right scores method. Consider the column of $\mathrm{DM}_{1}$. It is clear that the ranks assigned to c, d, and e is 5, 4, 3 . So the ranks assigned to ' $a$ ' and ' $b$ ' are 1 and 2 respectively. The ordinal rank matrices for $\mathrm{DM}_{1}$ are set as follows.

$$
\begin{array}{r}
\mathrm{R}_{1}=\begin{array}{l}
a \\
b \\
c \\
d \\
e
\end{array}\left(\begin{array}{lll}
4 & 1 & 2 \\
3 & 5 & 1 \\
2 & 2 & 4 \\
5 & 4 & 5 \\
1 & 3 & 3
\end{array}\right) \\
\mathrm{R}_{2}=\begin{array}{l}
a \\
b \\
d \\
d \\
e
\end{array}\left(\begin{array}{llll}
3 & 4 & 3 \\
5 & 5 & 4 \\
2 & 1 & 2 \\
1 & 2 & 1 \\
4 & 3 & 5
\end{array}\right)
\end{array}
$$




$$
\mathrm{R}_{3}=\begin{aligned}
& a \\
& b \\
& c \\
& d \\
& e
\end{aligned}\left(\begin{array}{lll}
5 & 4 & 3 \\
4 & 3 & 4 \\
1 & 2 & 1 \\
2 & 1 & 5 \\
3 & 5 & 2
\end{array}\right)
$$

Step - 4: The agreed matrix given thought $\mathrm{R}_{1}$ is set by a

$$
\begin{array}{r}
\mathrm{R}_{1}{ }^{1}=\begin{array}{l}
a \\
b \\
c \\
d \\
d
\end{array}\left(\begin{array}{llll}
5 & 1 & 3 & 5 \\
2 & 2 & 2 & 1 \\
1 & 5 & 5 & 4 \\
4 & 3 & 1 & 3 \\
3 & 4 & 4 & 2
\end{array}\right) \\
\mathrm{R}_{2}{ }^{1}=\begin{array}{l}
a \\
b \\
c \\
d \\
d \\
e
\end{array}\left(\begin{array}{llll}
5 & 2 & 3 & 3 \\
4 & 4 & 1 & 4 \\
1 & 5 & 5 & 1 \\
2 & 3 & 2 & 5 \\
3 & 1 & 4 & 2
\end{array}\right)
\end{array}
$$

Step - 5: Agreed matrices are converted into Borda score matrices

$$
\begin{array}{r}
\mathrm{B}_{1}=\begin{array}{l}
a \\
b \\
c \\
d \\
\\
e
\end{array}\left(\begin{array}{llll}
3 & 4 & 4 & 4 \\
4 & 0 & 1 & 0 \\
0 & 1 & 0 & 1 \\
1 & 2 & 2 & 3 \\
2 & 3 & 3 & 2
\end{array}\right) \\
\mathrm{B}_{2}=\begin{array}{l}
a \\
b \\
c \\
\\
d \\
e
\end{array}\left(\begin{array}{llll}
0 & 3 & 3 & 4 \\
1 & 1 & 0 & 2 \\
4 & 0 & 1 & 1 \\
0 & 2 & 2 & 0 \\
2 & 4 & 4 & 3
\end{array}\right)
\end{array}
$$

Step - 6: Score matrices are set by summing the values of each row.

$$
\begin{aligned}
& \left.\mathrm{Sm}_{1}=\begin{array}{l|c}
a & 15 \\
b & 5 \\
c & 2 \\
d & 6 \\
& 10
\end{array}\right) \\
& \left.\mathrm{Sm}_{2}=\begin{array}{l|c}
a & 10 \\
b & 4 \\
c & 6 \\
d & 4 \\
e & 13
\end{array}\right)
\end{aligned}
$$

Step - 7: In order to get the agreement matrix the values of $\mathrm{Sm}_{1}$ and $\mathrm{Sm}_{2}$ are ranked and form the first and second columns of the agreement matrix respectively.

$$
\left.\mathrm{R}_{\mathrm{G}}=\begin{array}{c|cc}
a & 3 & 1.3 \\
b & 5 & 5 \\
c & 4 & 3 \\
d & 1 & 4 \\
e & 1
\end{array}\right)
$$

Step - 8: Assume that the weight vectors of criteria are (0.7, 0.3 ). The collective weight agreement matrix is set as follows.

$$
\mathrm{R}_{\mathrm{G}}=\begin{gathered}
a \\
a \\
b \\
c \\
c \\
d \\
d
\end{gathered}\left(\begin{array}{cccccc}
0.6 & 0.9 & 0 & 0 & 0 \\
0.3 & 0.3 & 0 & 0 & 0 \\
0 & 0 & 0.2 & 0 & 0 \\
0 & 0 & 0.3 & 0.9 & 0.4 \\
0 & 0 & 0 & 0.3 & 0.6
\end{array}\right)
$$

or instance $\mathrm{a}_{11}=0.6, \mathrm{a}_{45}=0.4$ because rank 1 is assigned to alternative ' $a$ ' given the first criterion.

Step - 9: The assignment modal is formulated as follows.

$\operatorname{MaxZ}=0.6 X_{a 1}+0.9 X_{a 2}+0.3 X_{b 1}+\ldots \ldots \ldots+0.6 X_{e 5}$

Subject to $\sum_{i=a}^{e} x i \ell=1, \ell=1,2,3 \ldots \ldots \ldots . . .5$

Subject to $\sum_{\ell=1}^{5} x i \ell=1, i=a, b, c, d, e$

The optimal solution is $\mathrm{Xa}_{1}=\mathrm{Xb}_{2}=\mathrm{Xc}_{3}=\mathrm{Xd}_{4}=\mathrm{Xe}_{5}=1$. It means that ' $a$ ' has the highest production priority while' $d$ ' has the lowest one.

\section{CONCLUSION}

The improved algorithm benefits from the advantage of reaching optimal solution. In the previous researchers all inputs of the were considered as crisp values. The assumption is not in real cases. This paper considers product mix problem as a group decision making problem in which all inputs are fuzzy. In this paper, a new algorithm for optimizing product mix under fuzzy parameters is developed. For this method, ordering methods are used in order to make decision in a fuzzy group decision making environment. 


\section{REFERENCES}

[1] Aryanezhad.M.B and Rashidi Komijan.A (2004) "An improved Algorithm for optimizing product mix under the theory of constraints", International journal of production Research, 42, 4221-4233.

[2] Chen. S.J.and Hwang, C.L (1992) Fuzzy multiple Attribute Decision making, Springer-verlog.

[3] Fredendall, L.D and Lea, B.R (117) "Improving the product mix Heuristic in the of constrains", International journal of production research, 35, 1535-1544.

[4] Goldratt.E.M (1984) The Goal, Newyork, North River press.

[5] Hwang, C.L and Lin M.J (1987), Group decision making under multiple criteria, Springer-verlag.
[6] Lee.T.N. and Plenert, G(1993) 'Optimizing theory of constraints when new product Alternatives Exist' Production and inventory management Journal, 34, 51-57.

[7] Luebbe. And Finch. B (1992) 'Theory of constraints and linear programming 'A comparison International journal of production Research 30, 1471-1478.

[8] Patterson, M.C(1992) 'The product mix decision' A comparison of theory of constraints and Labor - Based management Accounting' prod and Inventory management journal 33, 80-85.

[9] Rashidi Komijan. A and Sadjadi, S.J (2005) 'Optimizing product mix in a multi - bottleneck Environment proceeding of International conference on computational science and its applications, suntec, Singapore, 388-396. 